\title{
Binocular Diplopia in Unilateral Aphakia: The Role of Botulinum Toxin
}

\author{
K. N. HAKIN and J. P. LEE \\ London
}

\begin{abstract}
Summary
We have treated 12 unilaterally aphakic patients, with a manifest squint and binocular diplopia, with botulinum toxin injection to the appropriate horizontal rectus muscle, in an attempt to reduce the angle of squint and thereby resolve the diplopia. In all cases a short-term reduction in the angle of squint was achieved. In nine patients, whose aphakia was corrected with a contact lens, and eight of whom had had their lenses removed because of trauma, this reduction was only temporary. In three patients, however, who had had a non-traumatic cataract removed, replaced with a posterior chamber implant, control of the deviation was maintained long after the acute effect of the toxin had disappeared, with the development of coarse binocular single vision, a fusion range, and abolition of all diplopia. The possible reasons for these different responses are discussed and it is suggested that in cases of binocular diplopia following lens extraction, botulinum toxin treatment should be considered prior to any extraocular muscle surgery, as temporary reduction of the deviation may be sufficient to allow recovery of binocular single vision.
\end{abstract}

It is well-recognised that a manifest squint may develop secondary to a cataract and that this squint may persist following removal of the cataract. A deviation may similarly result following removal of the crystalline lens, after blunt or perforating trauma. In either case, if the squint persists and the patient is unable to suppress the vision from either eye, diplopia will result. This can present a difficult management problem, as despite correction of the deviation with prisms or surgery, diplopia can persist due to the absence of central fusion.

Extra-ocular muscle injections of Botulinum Toxin $\mathrm{A}$ are commonly used to reduce the deviation in certain types of strabismus, typically consecutive or secondary divergent squints. The effect, however, is not permanent, usually lasting approximately two to six months only, the eyes rediverging as the toxin- induced muscular paralysis resolves. In some cases, however, the temporary straightening provided by the toxin injection may be sufficient to allow development of fusional control, previously absent, which keeps the eyes straight, long after the effect of the toxin has disappeared.

\section{Materials and Methods}

Twelve unilaterally aphakic or pseudophakic patients with a manifest horizontal squint who have been troubled by binocular diplopia were treated at the Botulinum Toxin clinic at Moorfields from 1985 to 1989. All patients received an orthoptic examination, with particular reference to binocular function, immediately prior to the injection. Under electromyographic control, a standard extraocular muscle dose of Botulinum Toxin A $\left(6.25 \times 10^{-4}\right.$ micrograms $)$ was injected into 
the appropriate horizontal rectus muscle, as previously described. ${ }^{1}$ Patients were reassessed at one or two weeks post-injection, and then again usually at around three months. Any improvement in diplopia, development of simultaneous perception, fusion, or stereopsis were noted. In most cases, conclusive decisions on potential binocular single vision could be made at the first post-injection visit, in which case no further follow-up was required.

\section{Results}

Of the 12 patients treated, eight patients had had a lens removed because of trauma-six as a result of a penetrating injury, and two a cataract secondary to blunt trauma. A contact lens was used to correct the aphakia in these cases. Two patients had had a senile cataract removed and an intraocular lens implanted, and two a uveitis cataract removed, one replaced with an intraocular lens and the other receiving a contact lens. Corrected visual acuities ranged from $6 / 6$ to $6 / 18$. The age at original surgery ranged from nine to 78 years, with a mean of 30.3 years, and a median age of 17 years. The average age of the patients in the traumatic group was 18.25 years, and in the non-traumatic group, 54.5 years. Time from surgery to correction of aphakia with a contact lens ranged from one

Table month to 14 years. Three patients had undergone extraocular muscle surgery following the original lens extraction prior to toxin injection:

Orthoptic assessment prior to toxin injection revealed a manifest divergent squint in 11 patients, ranging from eight to 40 dioptres, and a convergent squint in one patient, of 40 dioptres. On correcting the deviation with prisms or on the synoptophore, only three patients (all from the trauma group) exhibited any potential binocular function.

The results are summarised in the Table. The deviations were all markedly reduced, and in four cases, overcorrected, one or two weeks post-toxin injection. The change in deviation at this time ranged from nine to 75 dioptres, with a mean change of 30 dioptres. There were no local or systemic complications.

In the long-term, after the acute effect of the toxin had worn off, three patients maintained a reduced deviation, with binocular single vision in free space, and with no diplopia. All three had had a non-traumatic cataract removed, replaced with an intra-ocular lens. Two had a small esotropia with an additional latent element, and the other an exophoria; all had coarse stereopsis, and a demonstrable fusion range. Of the remaining patients, two did develop some binocular

\begin{tabular}{|c|c|c|c|c|c|c|c|c|}
\hline \multirow[b]{2}{*}{ No. } & \multirow[b]{2}{*}{ Age } & \multirow{2}{*}{$\begin{array}{l}\text { Reason for } \\
\text { lens extraction }\end{array}$} & \multirow[b]{2}{*}{$\mathrm{CL} / \mathrm{IOL}$} & \multirow[b]{2}{*}{ VA } & \multicolumn{2}{|c|}{ PRE-TOXIN } & \multicolumn{2}{|c|}{ POST-TOXIN } \\
\hline & & & & & Deviation & BF? & Deviation & BF?/Comments \\
\hline 1 & 40 & Blunt injury & $\mathrm{CL}$ & $6 / 5$ & $16 \mathrm{XT}$ & Yes & $2 \mathrm{XT}$ & No \\
\hline 2 & 17 & Perf. injury & $\mathrm{CL}$ & $6 / 6$ & $40 \mathrm{XT}$ & No & $\begin{array}{c}4 X T \\
(14 X T @ 3 / 12)\end{array}$ & $\begin{array}{l}\text { Synopt. only; } \\
\text { for surgery }\end{array}$ \\
\hline 3 & 15 & Perf. injury & $\mathrm{CL}$ & $6 / 18$ & $20 \mathrm{XT}$ & No & $10 \mathrm{XT}$ & $\begin{array}{l}\text { Occasional } \\
\text { for surgery }\end{array}$ \\
\hline 4 & 16 & Perf. injury & $\mathrm{CL}$ & $6 / 6$ & $40 \mathrm{XT}$ & No & $6 \mathrm{XT}$ & No \\
\hline 5 & 14 & Blunt injury & $\mathrm{CL}$ & $6 / 18$ & $25 \mathrm{XT}$ & No & 0 & No \\
\hline 6 & 9 & Perf. injury & $\mathrm{CL}$ & $6 / 18$ & $10 \times \mathrm{X}$ & Yes & $1 \mathrm{XT}$ & $\begin{array}{l}\text { Near BSV only; } \\
\text { distance BSV after } \\
\text { further toxin and } \\
\text { surgery } \times 2\end{array}$ \\
\hline 7 & 21 & Perf. injury & $\mathrm{CL}$ & $6 / 6$ & $8 \mathrm{XT}$ & Yes & $12 \mathrm{ET}$ & No \\
\hline 8 & 14 & Perf. injury & $\mathrm{CL}$ & $6 / 18$ & $12 \mathrm{XT}$ & No & $12 \mathrm{ET}$ & No \\
\hline 9 & 78 & Senile cat. & IOL & $6 / 9$ & $40 \mathrm{ET}$ & No & $\begin{array}{c}6 \mathrm{XT} \\
(8 \mathrm{ET} @ 3 / 12)\end{array}$ & Yes \\
\hline 10 & 51 & Uveitis cat. & $\mathrm{IOL}$ & $6 / 18$ & $40 \mathrm{XT}$ & No & $\begin{array}{c}35 \mathrm{ET} \\
(18 \mathrm{XT} @ 3 / 12)\end{array}$ & Yes \\
\hline 11 & 51 & Senile cat. & IOL & $6 / 12$ & $40 \mathrm{XT}$ & No & $\begin{array}{c}6 \mathrm{ET} \\
(2 \mathrm{ET} @ 3 / 12)\end{array}$ & Yes \\
\hline 12 & 38 & Uveitis cat. & CL & $6 / 6$ & $35 \times \mathrm{X}$ & No & $4 \mathrm{XT}$ & No \\
\hline
\end{tabular}


vision for near but maintained diplopia for distance. Following two further adjustable squint operations, one now has binocular single vision both for near and distance, and further surgery is planned for the other.

\section{Discussion}

Persistent binocular diplopia following cataract surgery can be a very difficult problem to manage, especially in cases of traumatic cataracts. In many cases, this is thought to be due to central disruption of fusion, where patients can momentarily superimpose two fusional targets when the deviation is corrected, but cannot 'lock on' and fuse the targets.

Pratt-Johnson and Tillson reported 24 patients with intractable diplopia following removal of a traumatic cataract. ${ }^{2}$ These patients had had their binocular function disrupted for at least $2 \frac{1}{2}$ years by the cataract, or by the uncorrected aphakia. The authors felt that central fusion disruption was the reason for the persistent diplopia, and that this was aggravated by the lengthy sensory deprivation. Jain et al., in another study, ${ }^{3}$ reporting on 28 children below the age of ten with unilateral aphakia, discovered that those fitted with a contact lens within eight months of trauma were more likely to recover normal binocular function. Ridley ${ }^{+}$and Lyle, ${ }^{5}$ in 1953 , emphasised the importance of the early fitting of a contact lens following cataract extraction, especially in children. Certainly, disruption of the fusion centre, postulated to be in the midbrain, is a potential reason for persistent diplopia. The fact that the three patients whose aphakia was corrected with an intraocular lens regained binocular function, may support the idea that the shorter the time of sensory deprivation, the greater the potential for restoration of binocular vision.

The age at surgery may be an influencing factor. The average age of the three patients who recovered binocular function was 60 years, and the age of those who did not, was just over 20 years. Research on rhesus monkeys has showed that there are different sensitive periods, during which monocular visual deprivation can affect vision for different functions. The sensitive period for binocular function was found to be longer than for rod and cone function, or monocular spatial vision. ${ }^{6}$ It may be the case, therefore, that binocular function can be affected at a much later age than that for amblyopia.

The presence of a cataract, or of uncorrected aphakia, may have a similar effect to occlusion of an eye. In an amblyopic eye, this can result in elimination of suppression and subsequent intractable diplopia. This elimination of suppression together with failure of fusion was termed 'horror fusionis' by Bielschowsky in $1935 .{ }^{7} \mathrm{He}$ attributed the problem to aniseikonia. This is certainly the case in patients with monocular aphakia corrected by spectacles, although Lubkin and Linksz have described 21 monocular aphakic patients who adapted to wearing spectacles, maintaining binocular vision, despite the high anisometropic aniseikonia. ${ }^{8}$ Pratt-Johnson and Tillson $^{2}$ tested all their patients for aniseikonia and stated that this was not a problem, whether the aphakia was corrected with a contact lens or intraocular implant. Hamed et al. ${ }^{9}$ reported 38 patients with persistent binocular diplopia after cataract surgery. Five of the patients were diagnosed as having a decompensated superior oblique palsy, despite no history of diplopia or a squint prior to cataract surgery. They suggested that restoration of visual acuity by cataract surgery may uncover a previously well-compensated deviation. In addition, they suggested that the brightness and colour disparity between the aphakic and phakic eye may also be a barrier to fusion.

What is the role of toxin in the management of these difficult cases? In a few, temporary reduction of the squint by the use of toxin can be sufficient to restore fusional control. As our successful cases demonstrate, the outcome cannot be predicted simply by orthoptic testing - of the three 'cures', two demonstrated constant suppression, and the other intermittent suppression, on testing prior to toxin injection, with no evidence of any binocular potential. Conversely, of the three patients who did exhibit binocular potential prior to injection, only one attained this, and then only after two further operations. Though our numbers are small, it may be that the older the patients, the more likely they will regain fusion and binocular vision. Recovery of binocular function may also be more likely if an implant is used, rather than a 
contact lens, to correct the aphakia-the aphakia is corrected immediately, and aniseikonia may be less of a problem. If a contact lens is used, then its prompt use following surgery might also increase binocular potential. The gradual deterioration in vision with a senile cataract may offer a better prognosis than the relatively sudden loss of vision that accompanies a penetrating injury or the development of a traumatic cataract.

Toxin also has a role in preventing unnecessary surgery. If the patient has no binocular vision following toxin injection, despite the eyes being straight, with an abnormal head posture if necessary, then surgery is extremely unlikely to offer any further benefit. Furthermore, surgery may simply bring the two diplopic images closer together, thereby confusing or distressing the patient, and therefore may actually prove to be disadvantageous.

Binocular diplopia following lens extraction is a relatively uncommon problem but the use of toxin should be considered, especially in elderly patients, either to produce a temporary reduction in the angle of squint, sufficient to allow recovery of binocular vision, or to provide information as to whether surgery is likely to be of any benefit.
Key words: Binocular diplopia, botulinum toxin, horror fusion, unilateral aphakia.

\section{References}

${ }^{1}$ Elston JS, Lee JP, Powell CM, Hogg C, Clark P: Treatment of strabismus in adults with botulinum toxin A. Br J Ophthalmol 1985, 69: 718-24.

2 Pratt-Johnson JA and Tillson G: Intractable diplopia after vision restoration in unilateral cataract. Am J Ophthalmol 1989, 107: 23-6.

'Jain IS, Mohan K, Gupta A: Unilateral aphakia in children: Role of corneal contact lenses. J Pediatr Ophthalmol Strabis 1985, 22: 137-9.

${ }^{+}$Ridley F: Contact lenses in unilateral aphakia. Trans Ophthalmol Soc UK 1953, 73: 373-86.

5 Lyle TK: The importance of orthoptic investigations before contact lens fitting in unilateral aphakia-a preliminary report. Trans Ophthalmol Soc UK 1953, 73: 387-98.

${ }^{6}$ Harwerth RS, Smith EL, Duncan GC, Crawford MLJ, Von Noorden GK: Multiple sensitive periods in the development of the primate visual system. Science 1986, 232: 235.

${ }^{7}$ Bielschowsky, A: Congential and acquired deficiencies of fusion Am J Ophthalmol 1935, 18: 925.

${ }^{x}$ Lubkin V and Linksz A: A ten-year study of binocular fusion with spectacles in monocular aphakia. Am J Ophthalmol 1977, 84: 700-7.

${ }^{9}$ Hamed LM, Helveston EM, Ellis FD: Persistent binocular diplopia after cataract surgery. Am J Ophthalmol 1987, 103: 741-4. 